\title{
Changes in mitotic reorientation and Wnt/AR signaling in rat prostate epithelial cells exposed to subchronic testosterone
}

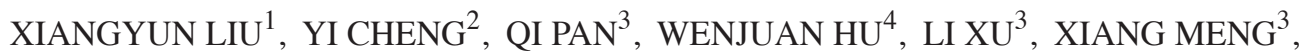 \\ JIANHUI WU ${ }^{3}$, CHENJING XIE $^{3}$, HAN YAN $^{3}$ and ZUYUE SUN ${ }^{3}$ \\ ${ }^{1}$ Key Laboratory of Exercise and Health Sciences (Shanghai University of Sport), Ministry of Education, Shanghai 200438; \\ ${ }^{2}$ Laboratory Testing Division, WuXi AppTec (Shanghai) Co., Ltd., Shanghai 200131; ${ }^{3}$ Department of Pharmacology and \\ Toxicology, Shanghai Institute of Planned Parenthood Research, Shanghai 200032; ${ }^{4}$ Department of Pharmacy, \\ Shanghai Children's Hospital, Shanghai Jiatong University, Shanghai 200040, P.R. China
}

Received October 17, 2014; Accepted September 18, 2015

DOI: $10.3892 /$ etm.2016.3044

\begin{abstract}
The aim of the present study was to investigate the changes in mitotic reorientation and relative differential gene expression in rat prostate epithelial cells following long-term exposure to testosterone propionate (TP). Sprague-Dawley rats were randomly divided into two groups as follows: TP group, which received $3.7 \mathrm{mg} / \mathrm{kg} /$ day TP for 30 days $(\mathrm{n}=10)$; and control group, in which rats were injected with olive oil $(n=10)$. Microscopic analysis of the prostate tissue was performed by immunohistochemical analysis and hematoxylin and eosin staining. Differential gene expression analysis was performed via gene microarray, and a total of five genes (Dkk3, Ran, Fas, Tgm4 and Wnt2) were selected and their expression levels were verified using reverse transcription-polymerase chain reaction. For rats treated with TP, mitosis was significantly reoriented, becoming parallel to the basement membrane. By contrast, in the control group cells mitotic orientation remained perpendicular to the basement membrane. Genes such as Ran and Tgm4 in the androgen receptor (AR) signaling pathway and Wnt 2 in the Wnt signaling pathway, were upregulated following treatment with TP. Conversely, the Dkk3 and Fas
\end{abstract}

Correspondence to: Dr Xiangyun Liu, Key Laboratory of Exercise and Health Sciences (Shanghai University of Sport), Ministry of Education, 188 Hengren Road, Shanghai 200438, P.R. China E-mail: h6yf@163.com

Dr Zuyue Sun, Department of Pharmacology and Toxicology, Shanghai Institute of Planned Parenthood Research, 2140 Xietu Road, Shanghai 200032, P.R. China

E-mail: szyue64@163.com

Abbreviations: AR, androgen receptor; TP, testosterone propionate; $\mathrm{BPH}$, benign prostate hyperplasia; H\&E, hematoxylin and eosin; Pca, prostatic carcinoma; RT-PCR, reverse transcription-polymerase chain reaction; SD, Sprague-Dawley

Key words: prostate, mitotic orientation, testosterone propionate, differential gene expression genes were downregulated following treatment with TP. In conclusion, mitotic orientation of prostate epithelial cells was altered following long-term administration of TP. Wnt and AR signaling pathways influenced cell proliferation and may have participated in the mitotic orientation change.

\section{Introduction}

Testosterone propionate (TP) is known to serve a crucial function in benign prostatic hyperplasia (BPH) and prostatic carcinoma (Pca). Pca is common in the developed world and is the most prevalent cancer among men in the USA. BPH is also a common disease in men $>50$ years of age (1). However, the mechanisms through which TP affects these processes are not clear. Mitotic orientation is generally perpendicular to the basement membrane in the glandular epithelium of control castrated rats; however, a recent study observed that mitotic orientation was parallel to the basement membrane in the glandular epithelium of castrated rats treated with TP (2).

TP is a sex hormone that primarily activates the androgen receptor (AR) (3), a key regulatory protein that is a critical intermediate in the intracellular androgen pathway (4). Chronic androgen stimulation may promote the expression and secretion of AR from epithelial cells. Additionally, prostate basal tissue may contain stem cells, and the aging and molecular injury mechanisms in stem cells are crucially involved in the development of age-associated diseases, such as BPH and cancer (5). Prostate basal cells are not dependent on androgen; however, the presence of androgen is able to induce the proliferation and differentiation of prostate basal cells (6), which is a key mechanism for the induction of prostate cell proliferation.

In order to elucidate the details of the mechanism(s) involved in changes in mitotic orientation in the prostatic glandular epithelium of castrated rats exposed to subchronic TP and the associated differential gene expression, an animal model was established in Sprague-Dawley (SD) rats (2). The aim of the present study was to determine the changes in mitotic orientation in SD rats that received long-term TP exposure and to compare the differences in gene expression between TP-treated and control rats using gene microarrays. 
Table I. Primers used in reverse transcription-polymerase chain reaction.

\begin{tabular}{|c|c|c|c|}
\hline Gene & $\begin{array}{l}\text { Bidirectional } \\
\text { primer sequence }\end{array}$ & $\begin{array}{c}\text { Annealing } \\
\text { temperature }\left({ }^{\circ} \mathrm{C}\right)\end{array}$ & $\begin{array}{l}\text { Product } \\
\text { length (bp) }\end{array}$ \\
\hline$\beta$-actin & $\begin{array}{l}\text { F: 5'-CCTCTATGCCAACACAGTGC-3' } \\
\text { R: 5'-GTACTCCTGCTTGCTGATCC-3' }\end{array}$ & 58 & 211 \\
\hline Ran & $\begin{array}{l}\text { F: 5'-CGTAGACGGTAAAGCAATGG-3' } \\
\text { R: 5'-AGTCAAAGAAGCAGCAAACAC-3' }\end{array}$ & 59 & 149 \\
\hline$D k k 3$ & $\begin{array}{l}\mathrm{F}: 5^{\prime} \text {-ACACCCAACAAGAAGCAACC-3' } \\
\text { R: 5'-AGGGAAAGAGGGAGAAAGC-3' }\end{array}$ & 59 & 174 \\
\hline Fas & $\begin{array}{l}\text { F: 5'-GACAACAACTGCTCAGAAGG-3' } \\
\text { F: 5'-TCAGAATAGTGTTTCCTGTCC-3' }\end{array}$ & 59 & 105 \\
\hline Tgm4 & $\begin{array}{l}\text { F: 5'-CGAGAACAGGCGTCAAGATA-3' } \\
\text { R: 5'-GTCTGTAGGTCAAGGGAGCAT-3' }\end{array}$ & 59 & 246 \\
\hline$W n t 2$ & $\begin{array}{l}\text { F: 5'-GTGCCGACTGGACAACTCCT-3' } \\
\text { R: 5'-ACCTCAGAATGCCCAAGACA-3' }\end{array}$ & 59 & 224 \\
\hline
\end{tabular}

F, forward; R, reverse.

In addition, the role of the Wnt and AR signal transduction pathways in prostate cell proliferation was evaluated by determining the expression of a number of associated genes.

\section{Materials and methods}

Experimental animals. A total of 20 male 4-month-old SD rats [certificate no.SCXK 2003-0002] were obtained from Shanghai Laboratory Animal Center of Chinese Academy Science (Shanghai, China) and housed in a specific pathogen-free room (temperature, $20-26^{\circ} \mathrm{C}$; humidity, $40-70 \%$ ), with free access to water and food. All procedures and animal experiments were approved by the Animal Ethical Committee of Shanghai Institute of Planned Parenthood Research (Shanghai, China) and complied with the Animal Management Rules of the Chinese Ministry of Health (document no. 55, 2001).

Establishment of a rat model for $\mathrm{BPH}$. Castrated rats were treated with subcutaneous injection of TP for 30 days at a dose of $3.7 \mathrm{mg} / \mathrm{kg} /$ day $(\mathrm{n}=10)$. Rats in the control group $(\mathrm{n}=10)$ were treated with an equivalent volume of olive oil $(100 \mu \mathrm{l})$. The prostate from each test and control rat was removed following the final treatment. All tissue specimens were removed under anesthesia (3\% Nembutal, $0.2 \mathrm{ml} / 100 \mathrm{ml}$; Sigma-Aldrich, St. Louis, MO, USA), and the specimens were fixed in formaldehyde solution and processed in paraffin. Paraffin blocks were cut into $5-\mu \mathrm{m}$ sections for hematoxylin and eosin $(\mathrm{H} \& \mathrm{E})$ and immunohistochemical staining.

Immunohistochemical staining procedure. Expression of AR was detected in prostate cells using immunohistochemical staining. Following deparaffination and rehydration of the sections, slides were placed in sodium citrate solution (0.01 M, pH 6.0) and heated to $96-100^{\circ} \mathrm{C}$ for $25 \mathrm{~min}$. After cooling, sections were incubated in $5 \%$ bovine serum albumin (Beijing Zhongshan Biological Technology Co., Ltd., Beijing, China) for $20 \mathrm{~min}$. The sections were then incubated for $2 \mathrm{~h}$ with primary rabbit anti-mouse AR monoclonal antibody
(1:100; cat. no. BA0004; Wuhan Boster Biotechnology, Ltd., Wuhan, China) diluted to 1:100 in phosphate-buffered saline (PBS) at room temperature. Following primary incubation, the sections were washed in PBS three times and incubated with horseradish peroxidase-conjugated goat anti-rabbit secondary antibody (1:50; cat. no. BA1051; Wuhan Boster Biolotechnology Co., Ltd.) for $30 \mathrm{~min}$ at $37^{\circ} \mathrm{C}$. Subsequently, the sections were washed with PBS and subjected to treatment with 3,3'-diaminobenzidine color-substrate solution and placed under cover slips. AR-labeled cells were observed using an Eclipse 50i light microscope (Nikon Corporation, Tokyo, Japan) in bright field mode.

Orientation of mitosis. For prostate epithelial cells, a parallel orientation was defined as the alignment of the chromosome axis and basement membrane at a $0-45^{\circ}$ angle. By contrast, a perpendicular orientation was defined as the alignment of the chromosome axis and the basement membrane at a $45-90^{\circ}$ angle. The cells were observed and imaged using the Nikon Eclipse 50i optical microscope, as described in a previous study (2).

Evaluation of differential gene expression by rat genome microarray analysis. Evaluation of differential gene expression was conducted using the Rat Genome 230 2.0 Array (Affymetrix, Inc., Santa Clara, CA, USA), which provides comprehensive coverage of the transcribed rat genome: 31,000 probe sets analyze the expression level of $>30,000$ transcripts and variants from $>28,000$ known rat genes. Total RNA was extracted using TRIzol reagent (Ambion; Thermo Fisher Scientific, Inc., Foster City, CA, USA) and its quality was confirmed using agarose-formaldehyde (Beijing Zhongshan Biological Technology Co., Ltd.) (7). Subsequently, double-stranded cDNA was synthesized from $5 \mu \mathrm{g}$ total RNA using the One-Cycle cDNA Synthesis kit (Affymetrix, Inc.), according to the manufacturer's instructions. Biotin-labeled cRNA was transcribed from the cDNA using the GeneChip ${ }^{\circledR}$ IVT Labeling kit (Affymetrix, Inc.). Labeled cRNA (15 $\mu \mathrm{g})$ was then fragmented and hybridized to the Affymetrix Rat 
A

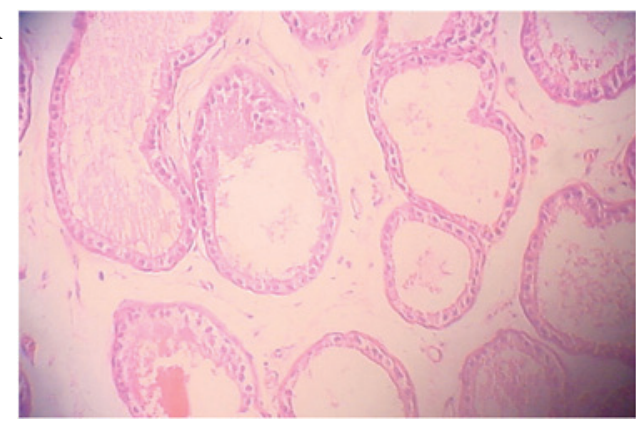

B

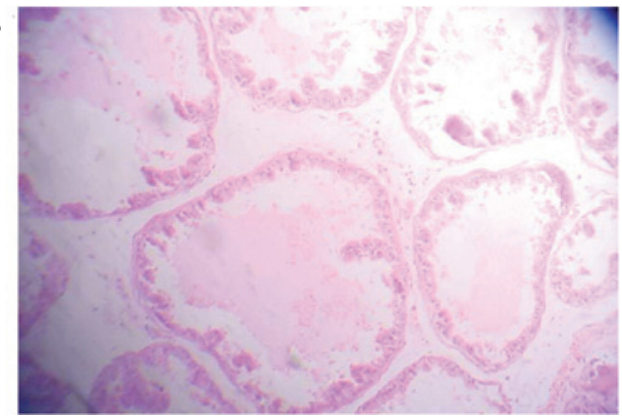

Figure 1. Prostate epithelia of the (A) control and (B) TP groups, stained with hematoxylin and eosin. Compared with the control group, the area of the prostate glandular cavity was significantly different in rats exposed to TP (magnification, x10). TP, testosterone propionate.

A

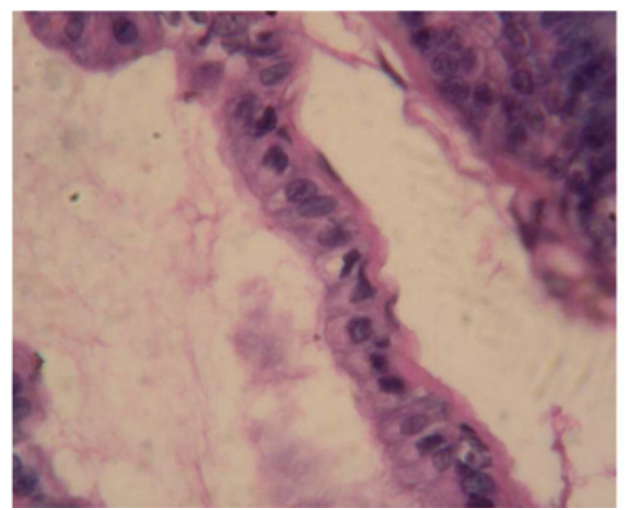

B

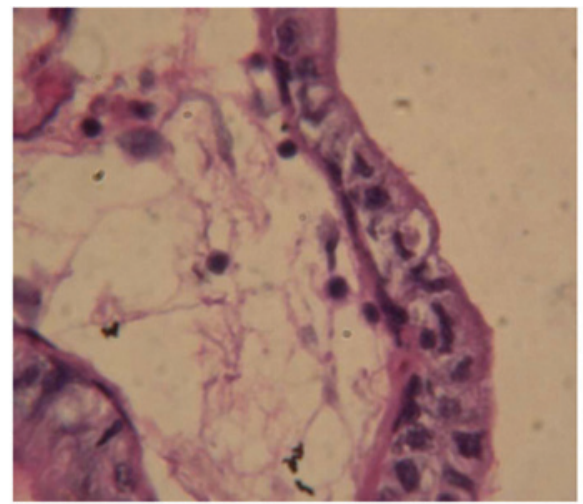

Figure 2. Mitotic orientation of prostate epithelia in the (A) control and (B) TP groups. Mitotic orientation of the prostate epithelium in the control group was perpendicular to the basement membrane, while that of the TP group was parallel to the basement membrane (magnification, $\mathrm{x} 400$ ). TP, testosterone propionate.

A

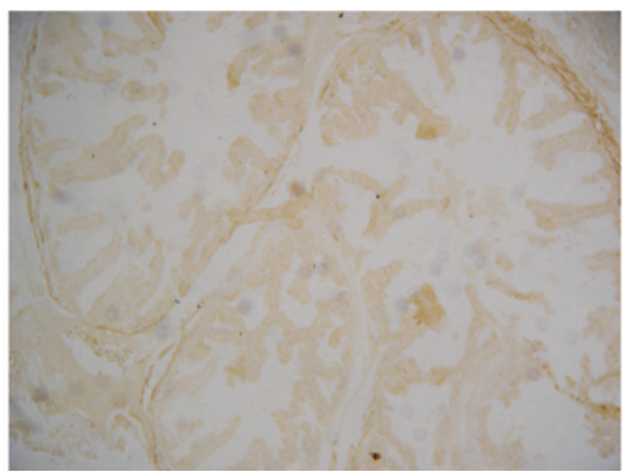

B



Figure 3. Analysis of AR expression in the (A) control and (B) TP groups. Brown-colored cells were positively stained for AR. Few AR-positive cells were seen in the control group, whereas increased AR staining was observed in the prostate glandular epithelia of the TP-treated rats (magnification, $\mathrm{x} 100$ ). AR, androgen receptor; $\mathrm{TP}$, testosterone propionate.

Genome 2302.0 Array for $16 \mathrm{~h}$ at $45^{\circ} \mathrm{C}$ in an Affymetrix GeneChip ${ }^{\circledR}$ Hybridization Oven 640 (Affymetrix, Inc.). The hybridized array was washed and stained in the GeneChip ${ }^{\circledR}$ Fluidics Station 450 (Affymetrix, Inc.), and fluorescent signals were detected using the Affymetrix GeneChip ${ }^{\circledR}$ Scanner 3000 (Affymetrix, Inc.). These data were initially documented with Affymetrix GeneChip ${ }^{\circledR}$ operating software GCOS 1.2 (Affymetrix, Inc.), which generated an expression report file.

Reverse transcription-polymerase chain reaction (RT-PCR) analysis of gene expression. Total RNA prepared for microarray analysis was also used for RT-PCR analysis. Total RNA $(2 \mu \mathrm{g})$ from each sample was subjected to reverse transcription using a Superscript First-Strand cDNA Synthesis kit (Henan Huamei Bioengineering Co., Ltd., Henan, China) according to the manufacturer's instructions. PCR was subsequently conducted by mixing $1 \mu \mathrm{l}$ cDNA, $2.5 \mu \mathrm{l} 10 \mathrm{X}$ PCR buffer, $1.5 \mu 125 \mathrm{mM}$ $\mathrm{MgCl}_{2}, 2.5 \mu \mathrm{l} 2.5 \mathrm{mM}$ dNTP, $1 \mu \mathrm{l} 10 \mu \mathrm{M}$ specific gene primer pairs, $1 \mu \mathrm{l} 10 \mu \mathrm{M} \beta$-actin or GAPDH primer pairs, $25 \mu 1 \mathrm{H}_{2} \mathrm{O}$ and $1 \mathrm{U}$ Taq polymerase (Ambion; Thermo Fisher Scientific, Inc.). The primers used in the PCR reaction are presented in Table I. PCR products were then amplified for 30 cycles, with each cycle consisting of the following steps: Denaturation for $10 \mathrm{sec}$ at $95^{\circ} \mathrm{C}$, annealing for $20 \mathrm{sec}$ at $72^{\circ} \mathrm{C}$ and polymerization for $5 \mathrm{~min}$ at $72^{\circ} \mathrm{C}$. The PCR products were resolved using an Affymetrix Hybridization Oven Model 640 (model 800138; 
Table II. Wnt- and AR-associated genes that were up- or downregulated following testosterone propionate treatment in rats.

\begin{tabular}{lclc} 
Probe ID & Gene & \multicolumn{1}{c}{ Character and function } & Regulation \\
\hline AT 1367590 & Ran & AR-associated protein & Up \\
AT 1371022 & Tgm4 & Pca-associated gene & Up \\
AT 1393927 & Wnt2 & Wnt signaling transduced element & Up \\
AT 1370328 & Dkk3 & Negative regulation element of Wnt & Down \\
AT 1397221 & $F a s$ & Apoptosis & Up \\
AT 1370163 & Odcl & Cell cycle control & Up \\
AT 1370235 & Dbi & GABA receptor regulation factor & Up \\
AT $1371150 t$ & Ccndl & Cell cycle control & Down \\
AT 1368785 & Pitx2 & Transcription regulation factor & Down \\
AT 1369788 & Jun & Transcription regulation factor &
\end{tabular}

AR, androgen receptor; Pca, prostatic carcinoma; GABA, $\gamma$-aminobutyric acid.

Table III. Reverse transcription-polymerase chain reaction analysis of the five selected genes and $\beta$-actin.

\begin{tabular}{lcc}
\hline Gene & Control & $\mathrm{TP}$ \\
\hline$\beta$-actin & $1.95 \times 10^{-3}$ & $2.66 \times 10^{-3}$ \\
Dkk3 & $2.93 \times 10^{-4}$ & $1.18 \times 10^{-5}$ \\
Ran & $1.07 \times 10^{-4}$ & $2.37 \times 10^{-4}$ \\
Fas & $9.47 \times 10^{-4}$ & $8.85 \times 10^{-6}$ \\
Tgm4 & $1.09 \times 10^{-4}$ & $2.46 \times 10^{-3}$ \\
Wnt2 & $1.24 \times 10^{-3}$ & $1.44 \times 10^{-4}$ \\
\hline
\end{tabular}

TP, testosterone propionate.

Affymetrix, Inc.) according to a DNA standard curve. Data were analyzed using Light Cycler 480 software version 1.5 (Roche Diagnostics, Basel, Switzerland).

Statistical analysis. Data were expressed as the mean \pm standard deviation. One-way analysis of variance (ANOVA) and P-values were used to evaluate significant differences between the groups. Image-Pro Plus 6.0 (Media Cybernetics, Inc., Rockville, MD, USA) was used to analyze image data. Data analysis to determine differential gene expression profiles was performed by importing MAS 5.0 intensity data (Affymetrix, Inc.) into the Partek Genomics Suite Version 6.4 (Partek Incorporated, St. Louis, MO) for ANOVA based on time in culture. $\mathrm{P}<0.05$ was considered to indicate a statistically significant difference. Post-hoc Fisher's exact test adjusted to correct for false discovery rates $(\mathrm{P}<0.05)$ was used to compare data from multiple groups. Only differentially expressed genes $(-2.0>$ fold-change $>2.0$; $\mathrm{P}<0.05)$ were included in each IPA core analysis.

\section{Results}

Mitotic orientation of prostate epithelia in rats. Prostate epithelia from TP-treated rats exhibited typical prostate proliferation morphology, in which the organ quotient, volume and area of the prostate glandular cavity were increased compared with the control group. H\&E staining revealed that the prostate epithelia were highly stylolitic, with intrusions in the glandular cavity, and the area of the prostate glandular cavity was large (Fig. 1). The mitotic orientation of prostate epithelial cells in TP-treated rats was parallel to the basement membrane, while the orientation in the control rats was perpendicular to the basement membrane (Fig. 2). These data demonstrate that the mitotic orientation of prostate epithelial cells changed following long-term exposure to TP.

Analysis of AR expression. Notably, immunohistochemical staining revealed an increased number of AR-positive cells in the prostate epithelia of the TP-treated rats when compared with the control rats (Fig. 3), indicating that TP treatment upregulated AR expression.

Results of gene chip microarray analysis. A rat genome microarray technique was used to analyze the differences in gene expression between the control and TP-treated rats. Genes that were altered in the TP group were assumed to be associated with changes in prostate cell mitotic orientation and proliferation. A number of the differentially expressed genes were associated with the AR and Wnt signal transduction pathways (Table II). Upregulation was observed in genes that promote cellular proliferation, including Ran, Tgm4, Odcl and Wnt2, while downregulation was observed in genes that inhibit cell proliferation, such as Dkk3 and Fas.

RT-PCR analysis of selected genes. To confirm the observed changes in gene expression, RT-PCR analysis was performed for a number of the genes, including Dkk3, Ran, Fas, Tgm4 and Wnt2 (Table III). The results of RT-PCR analysis were consistent with the microarray data.

\section{Discussion}

To the best of our knowledge, the present study showed for the first time that the mitotic orientation of rat prostate epithelial cells changes following exposure to TP for an extended period. 
In addition, a microarray analysis of over 28,000 rat genes, followed by verification using RT-PCR, indicated that the Wnt and AR signal transduction pathways were involved in the observed changes in the mitotic orientation of prostate epithelial cells in response to TP treatment.

The present study revealed that the mitotic orientation of rat prostate epithelial cells is altered following cell exposure to TP, providing a new method for the study of TP-dependent prostate cell proliferation. Additionally, the immunohistochemistry and $\mathrm{H} \& \mathrm{E}$ results of previous studies demonstrated that the prostate may be a target organ for TP $(8,9)$. Therefore, changes in cell proliferation may result from the reorientation of the mitotic complex following exposure of the prostate to TP. In a previous study, in control cells, mitotic orientation was parallel to the basement membrane; therefore, changes in proliferation may occur via the AR signal transduction pathway (10).

In the present study, TP-treated rats exhibited upregulation of Wnt 2 and other positive regulatory genes, while negative regulatory genes, such as $D k k 3$, were downregulated compared with the control group. The Wnt pathway has been widely studied $(11,12)$, and is crucially involved in numerous proliferative diseases, such as Pca. In the classical Wnt signaling pathway, Wnt2 stimulates cell proliferation and regulates the aging process of fibroblasts and epithelial cells. In addition, Wnt 2 signal reduction has been observed in senescent cells (13). Increased expression of Wnt 2 is able to stimulate prostate epithelial cell proliferation, activate the Wnt signaling pathway and cause changes in prostate epithelial cell polarity (13), which may result in chromosomal changes in prostate epithelial cells.

Dkk3 is a member of the Dkk family, which inhibits the Wnt signaling pathway by interacting with the LRP5/6 receptor and promotes lysosome endocytosis $(14,15)$. Although it has not been as well studied as Wnt, the $D k k 3$ gene has been shown to be downregulated in prostate tumor cells (16), suggesting that increased $D k k 3$ expression may inhibit tumor cells development (17). In the present study, TP-treated rats exhibited downregulated $D k k 3$ expression compared with the control group. As it is known that TP induces $\mathrm{BPH}$, it may be concluded that downregulation of the $D k k 3$ gene reduces the inhibition of cell proliferation and cell differentiation, in addition to causing BPH (18).

Tgm4 is a gene involved in the AR signaling pathway and is expressed in normal and abnormal prostate tissues. In numerous studies, Tgm4 has been shown to be a candidate marker for prostate cells $(19,20)$. In the TP group, Tgm4 upregulation promoted prostate cell proliferation. Additionally, TP treatment resulted in the downregulation of Fas, resulting in reduced apoptosis (21), and therefore enhanced prostate cell proliferation.

Ran is a member of RAS family and has been shown to be involved in the androgen signaling pathway in addition to the regulation of DNA transcription (22). Although numerous studies have investigated the association between Ran and prostate cancer (23), more recent studies have investigated Ran in the context of benign proliferation of prostate cells $(24,25)$. In the present study, the upregulation of the Ran gene was confirmed using RT-PCR, and the results suggested that Ran upregulation may contribute to prostate cell proliferation in $\mathrm{BPH}$.
AR serves a crucial function in the prostate and is coregulated by hormone/receptor combinations (26). Previous studies have demonstrated that numerous coregulatory events are associated with the Ras family. Furthermore, recent studies have reported that Ras response element binding protein 1 (RREB-1) is a ligand for AR and coregulates AR. Therefore, this Ras-associated protein has the potential to inhibit AR function. The Ras/MAPK kinase pathway is able to counteract RREB-1, inhibiting the androgen signaling pathway (27). As a member of the Ras family, Ran is involved in this inhibitory process and functions to promote prostate cell proliferation. In addition, Ran is involved in mitotic spindle organization and biogenesis, which may affect mitotic orientation of epithelial cells. In Ras-mediated transformation, Krüppel-like factor 5 regulates the cyclin B1/Cdc2 proteins, in addition to activating the cell cycle, and thereby promotes cell mitosis $(27,28)$. Thus, collectively, the present data suggest that TP treatment altered the mitotic orientation of prostate epithelial cells via a pathway involving Wnt and AR signaling. Further studies are required to determine the precise mechanisms through which Krüppel-like factor 5 is involved in this process.

In conclusion, mitotic reorientation of rat prostate epithelial cells was altered following exposure to subchronic TP, which may have promoted prostate cell proliferation via the Wnt and AR signaling pathways.

\section{Acknowledgements}

This study was supported by grants from the New Drug Major Program of China (no. 2011ZX09301-005), the National Natural Science Foundation of China (no. 11101077), the Shanghai 'Science and Technology Innovation Action Plan' Experimental Animal Research Project (nos. 11140901300 and 11140901302) and the Shanghai Key Lab of Human Performance (Shanghai University of Sport) (grant no. 11DZ2261100). The authors would like to thank Miss Dong-Mei Li, Mr. Lei Wang, Mr. Gui-Lin He, Professor Xiu-Rong Jiang, Professor Gui-Ming Liu, Dr Shu-Wu Xie, Dr Zhi-Ling Li and Dr Li Ma for their technical assistance.

\section{References}

1. Berry SJ, Coffey DS, Walsh PC and Ewing LL: The development of human benign prostatic hyperplasia with age. J Urol 132: 474-479, 1984.

2. Liu XY, Li DM, Zhang XF, Wu JH and Sun ZY: Mitosis orientation in prostate epithelial cells changed by endocrine effect. Acta Pharmacol Sin 29: 226-229, 2008.

3. Gao W: Androgen receptor as a therapeutic target. Adv Drug Deliv Rev 62: 1277-1284, 2010.

4. Chatterjee B: The role of the androgen receptor in the development of prostatic hyperplasia and prostate cancer. Mol Cell Biochem 253: 89-101, 2003.

5. Beltrami AP, Cesselli D and Beltrami CA: At the stem of youth and health. Pharmacol Ther 129: 3-20, 2011.

6. Isaacs JT and Coffey DS: Etiology and disease process of benign prostatic hyperplasia. Prostate Suppl 2: 33-50, 1989.

7. Mansour FH and Pestov DG: Separation of long RNA by agarose-formaldehyde gel electrophoresis. Anal Biochem 441: $18-20,2013$.

8. Vignozzi L, Gacci M, Cellai I, Santi R, Corona G, Morelli A, Rastrelli G, Comeglio P, Sebastanelli A, Maneschi E, et al: Fat boosts, while androgen receptor activation counteracts, $\mathrm{BPH}$-associated prostate inflammation. Prostate 73: 789-800, 2013. 
9. Xiang-Yun L, Ying-Wen X, Chen-Jing X, Jiu-Jiu W, Qi P, Bo G and $\mathrm{Zu}-Y u e \mathrm{~S}$ : Possible mechanism of benign prostatic hyperplasia induced by androgen-estrogen ratios in castrated rats. Indian J Pharmacol 42: 312-317, 2010

10. Hartman J, Ström A and Gustafsson JÅ: Current concepts and significance of estrogen receptor $\beta$ in prostate cancer. Steroids 77: 1262-1266, 2012.

11. Logan CY and Nusse R: The Wnt signaling pathway in development and disease. Annu Rev Cell Dev Biol 20: 781-810, 2004.

12. Polakis P: Wnt signaling and cancer. Genes Dev 14: 1837-1851, 2000.

13. Ye X, Zerlanko B, Kennedy A, Banumathy G, Zhang R and Adams PD: Downregulation of Wnt signaling is a trigger for formation of facultative heterochromatin and onset of cell senescence in primary human cells. Mol Cell 27: 183-196, 2007.

14. Levasseur R, Lacombe D and de Vernejoul MC: LRP5 mutations in osteoporosis-pseudoglioma syndrome and high-bone-mass disorders. Joint Bone Spine 72: 207-214, 2005.

15. Davidson G, Mao B, del Barco Barrantes I and Niehrs C: Kremen proteins interact with Dickkopf1 to regulate anteroposterior CNS patterning. Development 129: 5587-5596, 2002.

16. Abarzua F, Sakaguchi M, Takaishi M, Nasu Y, Kurose K, Ebara S, Miyazaki M, Namba M, Kumon $\mathrm{H}$ and $\mathrm{Huh} \mathrm{NH}$ : Adenovirus-mediated overexpression of REIC/Dkk-3 selectively induces apoptosis in human prostate cancer cells through activation of c-Jun-NH2-kinase. Cancer Res 65: 9617-9622, 2005.

17. Hsieh SY, Hsieh PS, Chiu CT and Chen WY: Dickkopf-3/REIC functions as a suppressor gene of tumor growth. Oncogene 23: 9183-9189, 2004.

18. Kawano Y, Kitaoka M, Hamada Y, Walker MM, Waxman J and Kypta RM: Regulation of prostate cell growth and morphogenesis by Dickkopf-3. Oncogene 25: 6528-6537, 2006.

19. $\mathrm{Li} \mathrm{H}, \mathrm{Wu} \mathrm{C}, \mathrm{Gu} X$ and Xiong C: A novel application of cell-free seminal mRNA: Non-invasive identification of the presence of germ cells or complete obstruction in men with azoospermia. Hum Reprod 27: 991-997, 2012.
20. Xu B, Harihan A, Rakshit S, Dressler GR and Wellik DM: The role of Pax2 in mouse prostate development. Prostate 72: 217-224, 2012.

21. Thielen JL, Volzing KG, Collier LS, Green LE, Largaespada DA and Marker PC: Markers of prostate region-specific epithelial identity define anatomical locations in the mouse prostate that are molecularly similar to human prostate cancers. Differentiation 75 : 49-61, 2007.

22. Ran L, He W, Zhu X, Zhou Q and Gou X: Comparison of fluid absorption between transurethral enucleation and transurethral resection for benign prostate hyperplasia. Urol Int 91: 26-30, 2013.

23. Newton CJ, Ran G, Xie YX, Bilko D, Burgoyne CH, Adams I, Abidia A, McCollum PT and Atkin SL: Statin-induced apoptosis of vascular endothelial cells is blocked by dexamethasone. J Endocrinol 174: 7-16, 2002.

24. Niehrs $\mathrm{C}$ and Acebron SP: Mitotic and mitogenic Wnt signalling. EMBO J 31: 2705-2713, 2012.

25. Nandan MO, Chanchevalap S, Dalton WB and Yang VW: Krüppel-like factor 5 promotes mitosis by activating the cyclin B1/Cdc2 complex during oncogenic Ras-mediated transformation. FEBS Lett 579: 4757-4762, 2005.

26. Antonarakis ES, Lu C, Luber B, Wang H, Chen Y, Nakazawa M, Nadal R, Paller CJ, Denmeade SR, Carducci MA, et al: Androgen receptor splice variant 7 and efficacy of taxane chemotherapy in patients with metastatic castration-resistant prostate cancer. JAMA Oncol 1: 582-591, 2015.

27. Mukhopadhyay NK, Cinar B, Mukhopadhyay L, Lutchman M, Ferdinand AS, Kim J, Chung LW, Adam RM, Ray SK, Leiter $\mathrm{AB}$, et al: The zinc finger protein ras-responsive element binding protein-1 is a coregulator of the androgen receptor: Implications for the role of the Ras pathway in enhancing androgenic signaling in prostate cancer. Mol Endocrinol 21: 2056-2070, 2007.

28. Choi HJ and Zhu BT: Critical role of cyclin B1/Cdc2 up-regulation in the induction of mitotic prometaphase arrest in human breast cancer cells treated with 2-methoxyestradiol. Biochim Biophys Acta 1823: 1306-1315, 2012. 